\title{
HE CANNOT CHOOSE BUT HEAR: THE PLIGHT OF THE CAPTIVE AUDITOR
}

\author{
CHARLES L. BLACK, JR.* \\ ... a si fatta pena, \\ che s'altra è maggio, mulla è si spiacente. \\ INF. VI, 47-8.
}

Science fiction has been called the literature of extrapolation. In the spring of last year one of the leading magazines devoted to the genre ran a serial, Gravy Planet, ${ }^{1}$ in which the title role is played by an Earth that has come to be dominated by the practices and philosophy of advertising. Common names for food and drink are heard no more; one raises, on Chicken Little and Coffiest, a family whose size is the result of precarious balance between the respective attractions of the promotional campaigns of a gynecological trade-association promising "Babies Without Maybes," and a proprietary formula known as PregNot. Functions of government are performed under the aegis of prestige-laden trade-names, to whose owners the great advertising agencies in midtown New York serve as ministries of propaganda; food inspectors wear armbands of a well-known supermarket chain, and there is a Senator, complete with phony Southern accent, from a soft drink. Advertising itself is ubiquitous; attending to its message is both a necessity and a felt duty of citizenship; objection is dangerous unorthodoxy.

I especially remember one sequence. On a plane in flight, the cabin windows are opaqued from time to time, and sound movies appear upon them, to extol and illustrate the merits of the vaunted (though, as it turns out, shoddy and worse) products of Gravy Planet material culture. In climax, an "olfactory" hammers home the urgency of purchasing a named deodorant, by filling the cabin with a life-like counterfeit of the consequences of its omission. A passenger unthinkingly expresses distaste, but hastens to explain that he didn't mean any harm. . . .

I stopped laughing just before the last installment came out. About that time, the Supreme Court uttered its judgment in the case of the Washington, D. C. "captive audience." 2 The captives at bar had become such by being

* Professor of Law, Columbia University.

1. Pohl and Kornbluth, Gravy Planet, Galaxy Science Fiction, June, July, August, 1952, republished sub nom. The Space Merchants (1953).

2. Public Utilities Comm'n v. Pollak, 343 U.S. 451 (1952).

The present article is not to be taken as a comment on the constitutional doctrine of the case, but on the value-problems and the problems of law in society raised by it. Since 
trapped in busses and by there being forced to listen to news, music, commercials, and other matter, all of such kind and in such proportion as seemed good to the captor bus company and its privies.

The Court rejected the contention, which had been sustained 3-0 in the District of Columbia Court of Appeals, ${ }^{3}$ that so to use objecting riders was to deprive them of liberty without due process of law. Douglas dissented wholeheartedly; Black, in part. Frankfurter disqualified himself, as being in his own person too outraged a victim of the captive audience scheme to sit in serene judgment. Burton wrote for the Court.

The facts of the very case were in no wise unique, unless paradox be thought sharpened by their having arisen in the capital city of a nation perilously dedicated to leadership in the fight of our century against the metamorphosis of homo sapiens into el hombre-masa. Despite occasional checks $^{4}$ the captive audience pattern threatens to spread through the sodedicated nation. ${ }^{5}$ In application to public transit, it works this way: The bus company is paid by entrepreneurs (a group of whom operates on a national scale) for allowing them to install FM receivers in (and loudspeakers inescapably throughout) its vehicles. The entrepreneurs line up an FM station, which broadcasts special programs to which the bus radios are fixedtuned. The passengers listen to what the people at the station want them to hear, whether they like it or not. Some like it. Some do not. Some exceedingly do not.

Advertisers support the scheme; testimony in the Washington case established that, during the time it covered, they paid a dollar a thousand people for a spot announcement. That they may continue their support, they have been assured, in one trade journal ad, "If they can hear-they can hear your commercial!"' The Washington station has described itself (again to the trade) as "delivering a guaranteed audience!"7

If your flesh crawls as did mine on first reading this phrase as applied to American citizens going about their lawful occasions in their national

the law is not quite so egregious an ass as some would have it, it is no accident that the issues of value and of efficacious legal working exhibit a parallelism to doctrinal issues, but the latter are not here under examination, and a nolo contendere is entered as far as concerns the doctrinal "correctness" (or, for that matter, "incorrectness") of the decision. Let those hunt the snipe who belseve in the bag.

3. Pollak v. Public Utilities Comm'n, 191 F.2d 450 (D.C. Cir. 1951).

4. The particular operation described herein is actually shrinking, the Washington broadcasts themselves having just been abandoned as "unprofitable." N.Y. Times, June $1,1953, \mathrm{p} .1, \mathrm{col} .1$. The factors that have brought this about are not now clear enough for analysis. Such a reverse does not affect the merits of the issues broached in this article.

5. The managers of the current scheme are standing by. Ibid. It would be unsafe to assume that a temporary set-back is the end-all of a pattern of action so tenaciously insisted upon in the past and so clearly at one with certain manifest emergent trends in civilization. Cir. 1951).

6. Quoted by the court in Pollak v. Public Utilities Comm'n, 191 F.2d 450, 454 (D.C.

7. Ibid. 
capital, ${ }^{8}$ then you will see why I think it only fair to throw up at this time any pretense of neutrality on the captive-audience question. I am revolted by the whole business. I see only one side to it. I think forced listening fits perfectly into the circumambient culture on those Volga steamers where, at last intelligence, it was a prominently featured amenity. ${ }^{9}$ But I tremble for the sanity of a society that talks, on the level of abstract principle, of the precious integrity of the individual mind, and all the while, on the level of concrete fact, forces the individual mind to spend a good part of every day under bombardment with whatever some crowd of promoters want to throw at it.

I think this practice raises issues of high principle. I say this at the start because the toughest obstacle to be gotten over, in dealing with the subject in a vein of earnestness, is precisely the often-encountered feeling that the whole matter, whatever its rights and wrongs, is rather triviala bit of a fuss about nothing. I suggest that this feeling, where present, may be in its origin associative rather than logical-that it fallaciously evaluates the interests invaded by forced listening in terms of the incontrovertible triviality and even trashiness of much of the stuff the captive audience has to listen to. To drag this association into the open is to rob it of force. Subjecting a man, willy-nilly and day after day, to intellectual forced-feeding on trivial fare, is not itself a trivial matter; to insist, by the effective gesture of coercion, that a man's right to dispose of his own faculties stops short of the interest of another in forcing him to endure paid-up banality, is not itself banal, but rather a sinister symbol of relative weighting of the independence of the mind of man and the lust to make a buck.

What follows may be regarded as only in a special sense a comment on the Supreme Court decision. I am not going to talk about the law of the case, but about the value-problems thereto subjacent. A few months ago, the New Yorker, long a front-line fighter against audience captivity, ran a lead paragraph in Talk of the Town, protesting the institution of forced listening on busses in Yonkers. In obvious allusion to the Washington case, the writer conceded that the would-be audience captor "has the Supreme Court behind him." 10 This just ain't necessarily so. The Court held, and could have held, only that the objecting captives could not find their deliverance in constitutional rights. One may disagree with that holding and still recognize that it does not amount to general approval of coerced listening, or to establishment of the right of the captor against all assailing. Every

8. See Crandall v. Nevada, 6 Wall. 35, 43 (U.S. 1867).

9. Margaret $K$. Webb in a letter to The New Yorker, Feb. 18, 1950, p. 85, col. 1. This letter should be read by those interested in the possibilities of extrapolation (and the wider cultural integrations) of audience captivity. And see ORWELL, 1984 (1949) passim.

10. The New Yorker, March 21, 1953, p. 27, col.1. 
avenue of protest, save one, remains as open as ever-letters to the editor, remonstrance to advertisers, complaint to the transit company, appeals to legislatures, councils and commissions-and where constitutional protection has failed these other modes of defense become even more important. The main question is still open, and always will be open: "Do we want this thing among us?" The Supreme Court cannot decide that for us.11

Still, the constitutional case posed issues within the framework of which questions of value may neatly be set. For when all the hemidemisemiquavers of doctrine had died in echo, the most substantial questions came down to this: "Does this sort of thing infringe the guaranty against deprivation of liberty, and, if it does, is government so implicated as to bring into play a guaranty good only against governmental action?" Breaking this down, and recasting it in the form of that new scrutiny of major premises which the radically novel case always induces: "What is liberty?" "What is it to deprive a man of liberty?" "What sort and degree of governmental involvement bring an encroachment on liberty under the ban?" And although these are problems in legal doctrine, no intelligent layman, and no responsible lawyer, will stand for their being left at that. Above each must be put a gloss that is not wholly or centrally of doctrine. First, as to "liberty," the rootsymbol of the Republic: "What are the freedoms, franchises, autonomies, integrities, the diminishment of which cheapens the worth of our citizenship and our humanity?" Secondly, since a forbidding of deprivation, to be worth the parchment it is written on, must really forbid that which really deprives: "What actions, in practical effect within the patterns of our society as it stands, frustrate or make unavailable our enjoyment of freedom?" And thirdly, given the multiform, complex and novel interventions of government in affairs: "What relations of sponsorship, enabling, or abetment, between government and the 'private' encroacher on freedom, ought to be looked on as amounting to a wrongful incidence, on individual man, of the power of the Entirety?"

Of this last question, in its application to the captive audience case, little need be said. (The Supreme Court assumed that governmental power was at least sufficiently implicated to force examination of the further issues.) ${ }^{12}$ The relations between private transit companies and public authority follow a set pattern in essentials; the Washington case was typical. The transit company holds a virtual monopoly, granted by the competent legislative body in implementation of considered public policy. ${ }^{13} \mathrm{~A}$ man has

11. And with careful explicitness disclaimed any intention of so doing. 343 U.S. at 465 .

12. Id. at 462 .

13. And, it may be added, of centrally important public policy. MacIver lists the "establishment and control of the forms of communication and transportation" as the second of the great functions of the State. MAcIver, THE MOdERN State 190 (1926). 
to ride the busses of the one company because governmental authority says they are to be the only busses to run. ${ }^{14}$ Monopoly is the same thing as absence of alternative to the customer; government is the grantor of transportation monopolies. Further, where audience captivity prevails, the administrative commission that acts as a governmental organ, charged with the task of policing the exercise of the granted monopoly power, has acquiesced in the use of that power to compel listening to the bus radio. Wherever doctrine may "draw the line," commonsense will refuse to see, in this pairing of prior empowerment by the State and subsequent ratification by the State, a purely "private" wrong, if wrong there be. Whatever coercion may inhere in the absence of a practicable alternative to the use of public transit is a coercion directly flowing from a set of arrangements which it has been an avowed public care to foster, and an accepted public responsibility to police. It is a coercion readied and confirmed by public action, and one of which the Entirety cannot wash its hands.

But is coercion present? Can a man be said to be "deprived" of his freedom not to listen, when he only has to listen because he "chose" to get on a bus? Bus companies would of course have us look on their relations with passengers as purely voluntary on both sides, so that the annexation of conditions to entering the bus can no more be looked on as coercive than can the setting by the offeror of the terms of any private offer. If I were going to argue doctrine, I should be happy to maintain that the notion underlying this claim, the notion, namely, that coercion cannot be found in the tendering of an extremely unpleasant or practically unavailable alternative to submission, is, in mid-twentieth century, a near-spent archaism even in law itself. ${ }^{15}$ But, law aside, when the Supreme Court finished for the day on the Monday our case was decided, what choice was really open to the attendants and clerks of court, to the not lavishly paid government attorneys, to the reference librarians in the Library of Congress across the way? Or to such people (i.e., nearly all of us) in any city large enough to attract the ministrations of the transit radio entrepreneurs? A taxi? Twice a day? (Have you read any good budgets lately?) Keeping a car and parking it downtown? Buying a nice house within walking distance of work, or moving into a close-by apartment, big enough for the family? Well, all those things may be possible "in contemplation of law." Abandoning that contemplation and looking about, we know they are virtually impossible, in contemplation

14. And to run, of course, (if we need a make-weight) on the common highways, existing legally as public easements and maintained physically by public funds.

15. Holmes puts the general point best: "But the fact that a choice was made according to interest does not exclude duress. It is the characteristic of duress properly so called." Union Pacific R.R. v. Public Service Comm'n, 248 U.S. 67, 70 (1918). The threat of refusal of services by a common carrier was early recognized as duress. See Dawson, Economic Duress-An Essay in Perspective, 45 Mrch. L. Rev. 253, 258-60 (1947) and cases cited. 
of fact, for most people working in a great city. Once the loudspeakers have blossomed on the bus wall, the only way most of us can avoid the daily taking of whatever they dish out is to throw up the job and leave town. That is the tendered alternative. That is the "or else. . . ." Horsesense as well as etymology is outraged by the suggestion that we have satisfactorily protected the integrities of our citizenship when people have to get out of the city to enjoy them. On the horsesense level, the substantial coerciveness of the captive audience scheme is not a debatable matter. Admen know this, and speak of guaranteed delivery.

As to both the questions just examined, we have to do with the eternal tug between form and substance. Form is a good thing in its place- on a bank check, say, or at the dinner table. Its place is decidedly not that of evaluating and guiding practice in the dealings of collective force with the private man. Most regimes and most societies succeed in being "perfectly legal"; the technique for attaining that modest goal consists in just one simple trick that always works: You seek the goal itself only "in contemplation of Something-or-Other," and you don't let the issue get confused by concrete social fact. This technique is not good enough if what we want is a society in which (to such sublunary approximation as our frailty allows) respect for individual integrity effectively prevails. In the sterner measure of the latter criterion, it is beyond doubt that, if a valuable human interest is invaded by making people listen daily to what somebody else thinks it well for them to hear, such invasion is right now being accomplished by coercion, and under the sanction of the State as representative of the social whole.

Which brings us to the crux. In court or out-whether in "construction" of the word "liberty" or in resolving whether the values it symbolizes are impaired - the crucial question has to be that of the worth and dignity of the interest the captive auditors bring to judgment. We face again the fact that many, at first glance, look on the plight and the plea of the objecting captive as somehow infra dignitatem in a constitutional context. Asking, above, why this should be so, I essayed partial answer, treating the question as one in psychological causation.

I now ask it again, but this time rhetorically! Why on earth should anyone committed to the central assumptions of our ethical life see anything picayune or petty in the claim of a man to dispose, as he will and as unavoidable circumstances allow, of his attention and of the faculties it marshals, as against the claim of a group of men to take this autonomy away from him for their own profit? The objecting captive is in fact defending one corner of a piece of ground that ought to be holy to all of us, if we make the smallest pretense of meaning what we say when we speak most seriously about the moral significance of our life as a nation. He is fighting in a novel quarter, 
for the means of general attack on the sector he defends came only lately into the hands of the aggressors. (I say "general" because coerced and unreplying attention to the words of another is known immemorially as an individual badge of servility.) But he is fighting, after all, for a very old freedom, a freedom to which, in some sense, all the others are dedicated handmaidensthe freedom of the mind. And the millenia rise up and cry out that he is forever right in going to war to defend that freedom the moment a new attack is mounted, no matter how large or small may be the force of which it at present disposes, and without regard to its being camouflaged in the motley of Madison Avenue.

I don't think it much matters what use any given rider might have made of his faculties during the time (for many people quite substantial) of their forced expropriation. Richard Burton used to memorize Old Persian vocabularies on busses. (In hideous irony, the record in the Washington case shows that, during the period it covers, he would have been forced to listen to wordy and patronizing solicitations to study at the Berlitz School, by which he would have been told-and, incredibly, I quote- "You need a language to keep up with the Joneses and with your business.") I would guess that some young men I have seen are dreaming of zootsuits and hot rods. Lots of people read books and magazines; some close their eyes and rest, or think about whatever they choose. A few seem to be shuffling and examining papers having to do with a forthcoming or just-finished day's work. Many peruse newspapers of their choice. Certain uses of the time one has to oneself by virtue of being in a crowd may be a good deal more frivolous than these. Others may be more serious; man remains a mystery, for all the adman's philosophy, and we cannot know for sure that no bus has ever run to Damascus. But the essential thing is that to be free in any regard is to be able to choose what use one will make of that freedom, whatever someone else might think of the value of the chosen activity. Miscellaneity of action, comprising inevitably some aimlessness and inanity, is the only visible body freedom possesses.

Forced listening attacks the mind's integrity with a new directness. Previous assaults have tended to the slow starvation of the mind through reducing the vitamin content in its fare, or to its frustration and atrophy through forbidding its exercise in expression. It was reserved for our time ${ }^{10}$ to produce that impresario whose happy blend of brash imagination and low cunning apprehended what was to be done by bringing to bear the combined

16. Classical antiquity affords one non-mythological parallel. Of Nero, we learn that "when he appeared [as a musician] publicly, his soldiers prevented the audience from leaving, though some jumped from windows and others feigned death in order to be carried out." ELSON, THE Book of MUSICAL KNowlEDGE 21 (1927). But the Neronian mode is distinguishable, at the least, by its forthrightness. 
crafts of the sound man and the advertising man on the coerced herdings of city life, and he has authored a technic that pushes more deeply, though no more painfully, into the minds of the unwilling than was possible to our ancestors' homely ways of censorship and suppression. A man can no longer fall back to the last wall of keeping his mouth shut and calling his mind his own. The sound, too loud and insistent to be ignored, in the place where he must be, now exacts, as a price of living a normal life in society, submission to the daily entry of whatever certain slick operators think he requires, in the way of entertainment, information, exhortation, instruction, scolding and even, as admen boast in their trade papers, "conditioning," which is to say, tampering. Let us not let the brassiness of manner, the sordidness of motivation, or the fast-talking speciousness in justification of those who have opened this road lull or bedazzle us into failing to note the direction it is taking. We have to do with an audacious deliberate attack on the central citadel of human personality. The mere discernment of what it is that is being attacked should, without more, lead us to condemn the whole scheme.

There is more, though closely connected. Man, we are told, is a rational animal. But we only know this because he is an animal that uses and understands language. Talk, like sex and death, is laughed about a lot, but if man has serious worth, then speech is a serious matter, for it is speech that maketh him manifest. Few shafts could strike with more on-target insult at the very manhood of humanity than its degradation into a collectivized object of speech, powerless to escape and powerless to answer. Much has been said and written, throughout the captive-audience controversy, on the relations between "freedom of speech" and "freedom from unwanted speech." The question whether the former includes the latter, as a matter of sound construction, is a technical one of great difficulty. What is perfectly clear is that the claim to freedom from unwanted speech rests on grounds of high policy and on convictions of human dignity closely similar to if not identical with those classically brought forward in support of freedom of speech in the usual sense. Forced listening destroys and denies, practically and symbolically, that unfettered interplay and competition among ideas which is the assumed ambient of the communication freedoms. It contradicts, moreover, what some would regard as a deeper though not often spoken ground for letting people say freely what they choose to say-respect, namely, for each man as a person, in his uniquely human and finally mysterious function as user of language. For respect, like liberty, is indivisible, and most obviously so when fine divisions are sought to be made in the same life-context. A society which uses toward its members the wanton contempt of treating their listening to words as a thing, to be reduced to possession and sold in 
carload lots at a dollar a thousand, cannot long hold fast to a contradictory respect for their utterance of words as something inviolably close to the center of man as man.

Forced listening rigs the market in ideas, for it heavily and arbitrarily favors those communications agreeable to its managers. Since its managers are advertisers or those who act in the interest of advertisers, the tendency of the market-rigging cannot be guessed at without some reference to advertising itself. Let me repeat that the triviality and worse of commercials tends to no extent whatever to imply the triviality of being forced to listen to them. The implication, I insist, is to the contrary: It is the more offensive to the dignity of a human being to force his submission to attempted implantation of signal reactions; to contrived insult to his taste and intelligence; to the beating of the drum that tells him to Do It . . . Today; to the piping of the fife that seeks to set up in his spine a cortically unacceptable (and viscerally nauseous) association linking a company that has been in trade for 76 years with the Spirit of '76; to the suggestio falsi of the "three out of four physicians interviewed"; to the whole disgusting prelogical plucking at the strings of shame and vanity and fear.

But the market-rigging function of forced listening suggests attention to another side of advertising. It has, its exponents tell us, a Philosophy, a Way, and even (for an adman stops at nothing) a Gospel. One Article of Faith in this Gospel emerges as a matter of soundest induction, commercial by commercial: Prices were never so reasonable, products never so fine, and the lot of you folks out there never quite so roseate in hue. We know another Article well, for it is the easily tallied integral sum of all advertising, and its deepest philosophic wellspring: Material possessions produce happiness. (Symmetry is thereby served, for another Gospel has much to say to the same proposition.) Whatever admen might admit or deny, advertising as we know it contains, as a net matter, these two implications, and one could probably add a few more of connected tendency and comparable generality.

Now to pound such implications into the heads of those who have to listen is not merely to make a pitch for one product after another. It is to implant attitudes and even implicity to communicate views on arguable matters of weight and of public interest. The adman has every right to preach his Gospel, and to insinuate advocacy of the following of his Way. But is it consonant with any notion of free competition among ideas, or, indeed, of freedom of any kind, that all of us should be forced to hear him or become hermits? That is not true, and no one would dare suggest it be made true, of any other Way, or of any other Gospel.

As to "news" the case is even clearer, for controversiality, of subject 
matter at least, is manifest. All "news" is and has to be biassed, for it is the end product of choices among literally uncountable subjects, aspects, arrangements, words, and, on radio, tones of voice. Diversity of sources, and unhandicapped competition among them, are our safeguards. ${ }^{17}$ Of these we have, in sooth, no expendable surplus. But forced listening to one version, whether of "fact" or "comment," rigs this particular corner of the market to an unprecedented degree. ${ }^{18}$

The more I have thought about this captive audience business, the more it has seemed to me that the case against it can be summed up in a single sentence: It doesn't fit in. The disconformity is general, outreaching illustration. It is impossible to read Mr. Justice Douglas' dissent in the Washington case without feeling that, whatever the merits of the technical constitutional issues, here speaks the voice in full and unembarrassed harmony with the best our culture has had to say. It would be an awkward, stumbling job to try to explain to a well-disposed foreign visitor that audience captivity is not just "perfectly legal" but fully consonant with those of our aspirations and practices of which we are proudest before the world.

A few defenses have been offered. One of them, to which I shall assign the number "zero," runs to the effect that riders don't really have to pay attention, but may withdraw their minds at will, the whole thing being "psychological." I don't think it worth while to discuss such a defence when it is put forward by those who have marshalled every resource of societal pressure, technology, and applied psychology to the precise end of making the withdrawal of attention as difficult as possible-who have even installed, as one trade ad brags, ${ }^{19}$ a special device to boost volume when the commercial comes on. Under the same number, let's throw in the attempt at equating the loudspeakers with car posters or highway signs; that argu-

17. See Times-Picayune Pub. Co. v. United States, 345 U.S. 594, 602 (1953), expanding this theme and citing the words of Learned Hand, $J$. , in United States v. Associated Press, 52 F. Supp. 362. 372 (S.D.N.Y. 1943), where he speaks of the press as serving "one of the most vital of all general interests: the dissemination of news from as many different sources, and with as many different facets and colors as is possible. That interést is closely akin to, if indeed it is not the same as, the interest protected by the First Amendment; it presupposes that right conclusions are more likely to be gathered out of a multitude of tongues, than through any kind of authoritative selection. To many this is, and always will be folly; but we have staked upon it our all."

It is hard to imagine a selection more authoritative than one to which most people must listen, almost every day.

18. All the above points can be expanded in many directions. We need only think of busses to think of school children, Everson v. Board of Education, 330 U.S. 1 (1947), and the collocation of the two, in the constitutional field of reference in which they have met, brings to mind the parental claim to select the indoctrinations the child shall or shall not receive. Children do ride busses, and they must ride them, as Everson reminds us. Yet if a parent prefers that his child not be taught to envy his neighbors' possessions, and he honestly believes that this is a part of the advertising message, or if he had as soon Junior were not told to nag Mommy into buying Studgies and a smart adman thinks of telling Schoolbound Junior to do just that, is the parental claim de minimis?

19. Cited by the court in Pollak v. Public Utilities Comm'n, 191 F.2d 450, 454 n.5 (D.C. Cir. 1951). 
ment might convince a being from Mars fresh off the spaceship, but most of us Terrans are aware that you can close or avert your eyes, but cannot close your ears or avoid hearing what is in the air around them.

The other defenses may be at least worth numbering. It is said, first, that most riders like the stuff. Tame "surveys" have been taken, and produced their unsurprising results. Other surveys have seemed to contradict these results. Surveys are not, after all, the last word in the matter, whatever their outcome, for if our nation is committed to anything it is to the ranking of some interests as beyond the reach of majority preference, and the question would still subsist whether the interest asserted by the dissenting captive, as above characterized, ought to be one of these. But no survey has taken into account, in the framing of its questions, the difference (one which precisely marks civilized man) between merely liking something and insisting on what you like at whatever cost to others. For no survey has solicited or tabulated the answer to this question: "Even if you enjoy these broadcasts, as far as your own tastes go, do you want to continue to be amused if a good many of your fellow passengers are deeply outraged by them?" It is hardly complimentary to a civilized population to assume that the answer would be in the affirmative - and hardly hopeful for the actual existence of those feelings of respect for others which we like to think our society embodies. I have faith that a great majority of our people would not wish to purchase relief from tedium with the coin of others' anguish and felt insult.

Secondly, we are reminded that liberty is never absolute, but always "qualified." Yes, but how? In this as in many contexts the sound gloss on "qualified" is "subject to abridgement for good public cause." There is where the audience captors get into trouble. Of course we would all acquiesce in the enforced assembly of the population to listen to air-raid instructions. But what has that to do with the delicious T-bone steak at the Fat Boy Restaurant?20

Thirdly (and with climactic speciousness), it is pointed out that a good deal of noise, verbal and non-verbal, is inescapably incidental to city life, and that this, after all, is just one noise more. But the bus-radio scheme is not inescapably incidental to anything else, but rather itself a contrivance precisely aimed at the coercion of listening. What would we think of a man who turned a hose on passers-by, and defended his action on the ground that people in those parts were often caught in the rain? The argument, as argument, falls flat on its face, but the facts it brought with it get up and march in the opposite direction. Privacy and freedom from distraction are indeed

20. It was suggested at one stage in Pollak that the radio apparatus might come in handy in an emergency. Cf. Lamb, $A$ Dissertation Upon Roast Pig (1822). 
rare in modern life; ${ }^{21}$ the spoliation of what remains of them is hence the more injurious. ${ }^{22}$

In all cases, but most of all in the case where trouble is made and decision forced, social action is not just action, but symbol as well. Forced listening goes on among us. Its more than patentness enhances its symbolic function; where it prevails it is something everybody is sure to notice as a prominent feature of our life. The Supreme Court has validated it against constitutional attack and, as the New Yorker comment ${ }^{23}$ shows, that validation will publicly be taken to reach wider than it does. We have mostly acquiesced in it-at least we have not, as we should have done, screamed about it until no adman would touch it with a ten foot pole. ${ }^{24}$ I don't like any of these things as facts. But I more than dislike what they seem to symbolize, as to the values held in action among us, in the teeth of our professions. And I am disturbed by the docility with which those professions, when an issue like this comes up, behave themselves and stick home in their abstract empyrean, leaving concrete social fact alone.

We hire halls in which to tell one another how much we respect the Mind of Man. But as Man rides the bus home from the lecture, what is the bus radio saying, beneath its acquiesced-in blarings, in the solemn gesturelanguage of the deed?

Something like this, I am afraid: That the mental and spiritual integrity of the citizen will not be insisted on to ridiculous extremes, if it gets in the line of march of the fast buck; that a human being, if he happens to be in a crowd, is properly to be treated as a means rather than as an end, as a commodity rather than as a person, not as a unique subject but as a fungible object, promised for daily delivery guaranteed; that intellectual insult is after all de minimis, and to resent it is to make a tempest in a teapot; that our culture, without missing a stitch, can accommodate among its normative and behavior systems a new pattern (hitherto associated with rather

21. Surcease from advertising itself may yet acquire a high scarcity value, In an article entitled No Hiding Place, Time, Oct. 17, 1949, p. 75, col. 1, reports on a (self-explanatorily named) Storecast Corporation of America. Indeed, the stage is set for cashing in. A New York man has patented a jukebox that blares commercials unless fed with nickles. Newsweek, Feb. 23, 1953, p. 65, col. 1.

The general trend has many symptoms: "In Peoria, Illinois, a daily music program is piped into the reading rooms of the Public Library. . . ." The New Yorker, May 2, 1953, p. 21, col. 1. Frederick Othman reports on a device enabling the station to turn on home sets at will, Too Quick Switch, N.Y. World-Telegram and Sun, Nov. 14, 1951, p. 27, col. 1 .

22. As to all these points it might not be improper to import the wise words of the court in Rochin v. California: "We are not unmindful that hypothetical situations can be conjured up, shading imperceptibly from the circumstances of this case and by gradations producing practical differences despite seemingly logical extensions. But the Constitution is "intended to preserve practical and substantial rights, not to maintain theories." 342 U.S. 165, 174 (1952).

23. The New Yorker, March 21, 1953, p. 27, col. 1.

24. Since the above was, written, the ten-foot pole market may be trending upward. See note 4 supra. 
different cultures) the aim and effect of which is to make of our people a herd handily corralled for whatever purpose certain resourceful gentlemen may think proper and of profit; that, when protest is stirred against such a paradox, quite enough answer has been made when it has been justified formally, in terms of the elegantia juris or of layman's legalism, whatever may be the inelegant facts of the matter.

I do not suggest that, in our acquiescence to audience captivity, we have decisively accepted the value-judgments it symbolizes. One bad custom cannot corrupt the world. But as long as it prevails, our manifest practice daily and deeply contradicts our professions, and that is a dangerous matter. For something always gives, and too of ten it is the professions, or, more insidiously, the sincerity with which they are held, or the wideness of their understood extent.

Leaving the analysis of this and that interest, of this and that value, I would be content to stake the whole case on a judgment in what might almost be called the aesthetics of societal action, a judgment as to the felt rightness or wrongness of one picture from our life. One morning this spring, in the capital of our Republic, people in thousands were seated and standing in vehicles where, because of the very structure of life and work, they had to be. Through all the vehicles, and into all the ears, came a single voice. And the voice said the same thing, and all the people listened to the same thing, in galled or docile obedience-down Pennsylvania Avenue, and near the Station, and past the Memorial and the Monument, and by fountains and waters, and on a hundred lesser streets, all over town. 